\title{
Intussusceptive Angiogenesis: A Biologically Relevant Form of Angiogenesis
}

\author{
Ward De Spiegelaere ${ }^{a}$ Christophe Casteleyn ${ }^{b}$ Wim Van den Broeck ${ }^{c}$ \\ Johanna Plendl $^{d}$ Mahtab Bahramsoltani ${ }^{\mathrm{e}}$ Paul Simoens ${ }^{c}$ Valentin Djonov $^{\mathrm{f}}$ \\ Pieter Cornillie ${ }^{c}$

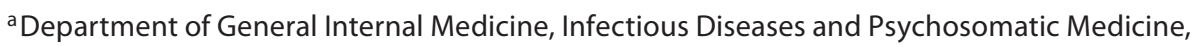 \\ Ghent University Hospital, Ghent, ${ }^{\mathrm{b}}$ Laboratory of Applied Veterinary Morphology, Department of Veterinary Sciences, \\ University of Antwerp, Antwerp, ' Department of Morphology, Faculty of Veterinary Medicine, Ghent University, \\ Merelbeke, Belgium; ${ }^{d}$ Department of Veterinary Anatomy, Faculty of Veterinary Medicine, Freie Universität Berlin, \\ Berlin, e Department of Anatomy, Histology and Embryology, Faculty of Veterinary Medicine, Universität Leipzig,



\section{Key Words}

Angiogenesis · Sprouting • Cooption - Vascular mimicry models for investigating intussusceptive angiogenesis are summarized. In addition, other mechanisms of vascular growth are briefly reviewed.

Copyright $\odot 2012$ S. Karger AG, Basel

\begin{abstract}
Angiogenesis, i.e. the development and growth of blood vessels, is a major topic of research as it plays an important role in normal development and in various pathologies. Recent evidence revealed the existence of different mechanisms of blood vessel growth, including sprouting and intussusceptive angiogenesis, vascular mimicry, and blood vessel cooption. The latter two have only been observed in tumor growth, but sprouting and intussusceptive angiogenesis also occur in healthy, physiologically growing tissues. Despite this variety of angiogenic mechanisms, most of the current research is focused on the mechanism of sprouting angiogenesis because this mechanism was first described and because most existing experimental models are related to sprouting angiogenesis. Consequently, the mechanism of intussusceptive angiogenesis is often overlooked in angiogenesis research. Here, the mechanism of intussusceptive angiogenesis is reviewed and the current techniques and
\end{abstract}

\section{Introduction}

Angiogenesis is very prominent in developing and growing organisms. In the adult, it is only active in specific situations and tissues, such as in wound healing, in the cyclic ovary, and in the life cycle of the female mammary glands and uterus. It is also associated with diverse pathological conditions, in which it can have a positive or negative impact on the pathological process $[1,2]$. Angiogenesis can repair damage inflicted by ischemia or cardiac failure, but in certain situations the activation of angiogenesis may aggravate the pathology [3]. Examples of the latter are tumor growth and cardiovascular diseases such as atherosclerosis, chronic inflammation, diabetic retinopathy, psoriasis, endometriosis, and rheumatoid arthritis $[4,5]$. The mechanism of angiogenesis has been

\section{KARGER}

Fax +41613061234 E-Mail karger@karger.ch www.karger.com (c) 2012 S. Karger AG, Basel

$1018-1172 / 12 / 0495-0390 \$ 38.00 / 0$

Accessible online at:

www.karger.com/jvr
Dr. Ward De Spiegelaere

Department of General Internal Medicine, Infectious Diseases and

Psychosomatic Medicine, Ghent University Hospital

De Pintelaan 185, BE-9000 Ghent (Belgium)

Tel. +32 9332 0697, E-Mail Ward.DeSpiegelaere@UGent.be 
recognized as a promising therapeutic target that has to be enhanced or inhibited, depending on the pathology [ 1 , $6,7]$. Consequently, a better understanding of the process of angiogenesis will help the development of pro- and antiangiogenic therapies.

Until recently, the process of angiogenesis was thought to mainly proceed through the so-called sprouting of blood vessels from the pre-existing vasculature. However, different mechanisms of angiogenesis have been discovered $[8,9]$. In physiologically growing tissues, two forms of angiogenesis have been described, i.e. sprouting angiogenesis (SA) and intussusceptive angiogenesis (IA). SA was initially thought to be the only process of angiogenesis, but in the last decade of the previous century IA was discovered as an alternative process $[10,11]$. SA is purely responsible for vascular growth, whereas IA can also involve vascular remodeling through pruning of excessive blood vessels. In addition to these mechanisms, two alternative forms of angiogenesis have been described, i.e. vascular cooption and vascular mimicry, but these mechanisms are assumed to be restricted to pathological situations $[8,9]$. The heterogeneity of angiogenic processes should be taken into account in future antiangiogenic therapies since recent data revealed that the angiogenic phenotype may switch to a different form of angiogenesis after angiogenic treatment $[8,12]$. In addition, a better knowledge of these forms of angiogenesis can lead to further fine-tuning proangiogenic therapy to re-establish a functional vascular network in ischemic tissue [9].

Because IA is underrepresented in the recent literature, the present review mainly focuses on this form of angiogenesis. In this context, SA is briefly reviewed, but other extensive reviews are available [7, 13]. Furthermore, alternative forms of vascular growth, including vascular mimicry and vascular cooption, are briefly reviewed.

\section{Sprouting Angiogenesis}

SA is a complex process in which a vascular sprout arises from a pre-existing vessel and subsequently forms a new blood vessel. This mechanism is mainly regulated in a paracrine fashion by angiogenic growth factors that are expressed by hypoxic tissues $[4,9]$. SA starts with vessel dilatation and an increase in vascular permeability to allow extravasation of proteins that partly disrupt the endothelial basement membrane and lay down a provisional scaffold for migrating cells [14]. This enables endothelial cells, pericytes, and vascular smooth muscle cells to detach and migrate towards angiogenic stimuli. The en- dothelial cells start to proliferate and form a lumen. As such, a vascular sprout develops and fuses with another sprout or another blood vessel. Finally, the endothelial cells stop proliferating and mature by binding to each other, to the surrounding pericytes, and to the basement membrane $[15,16]$. SA is a highly invasive process that allows the formation of a vascular network within previously avascular tissues, such as the hypertrophic zones of the cartilage in the growth plate of growing endochondral bones, or in diverse pathological settings including tumor growth $[13,17]$.

The constitution of angiogenic sprouts has been intensively studied [13, 18-21]. Three types of cells are recognized in the growing vascular sprout, i.e. tip cells, stalk cells, and phalanx cells (fig. 1) [13]. An angiogenic sprout contains a single tip cell that is located at the apex of the sprout. Using their numerous filopodia, tip cells scan the environment for angiogenic stimuli and guide the angiogenic sprout in the direction of these stimuli. Stalk cells trail just behind the leading tip cell and do not bear filopodia. These cells proliferate at a high rate; they start the process of lumenization and they contribute to the formation of the capillary basement membrane. During maturation, stalk cells transform into phalanx cells, which are so called as they form an ordered monolayer of endothelial cells reminiscent of the military 'phalanx formation' of the ancient Greek soldiers [22]. Phalanx cells proliferate at a slower rate than stalk cells. They share the morphological characteristics of quiescent endothelial cells but continue to form the basement membrane and enhance the tight junctions. Phalanx cells form a tight barrier between the blood and the surrounding tissue [13].

Upon activation with vascular endothelial growth factor (VEGF), the endothelial cells compete with each other to become the leading tip cell of the capillary sprout [18]. This competition is mediated through VEGF-induced expression of the delta-like ligand 4 (DLL4) protein via the VEGF receptor VEGR2. Subsequently, DLL4 activates the Notch pathway in nearby endothelial cells. As Notch induces VEGFR1 and inhibits the expression of the VEGF receptors, VEGFR2 and VEGFR3, it suppresses the adjacent cells to become tip cells [21, 23-25]. These mechanisms limit the number of tip cells to one per sprout and inhibit the formation of excessive angiogenic sprouts. Apart from a high expression of VEGFR2 and VEGFR3, tip cells also express high levels of platelet-derived growth factor beta polypeptide (PDGFB) which is known to play a role during pericyte recruitment [19]. In addition, recent work by del Toro et al. [26] revealed that tip cells express three groups of proteins, including pro- 
Fig. 1. Schematic illustration of the mechanism of SA.

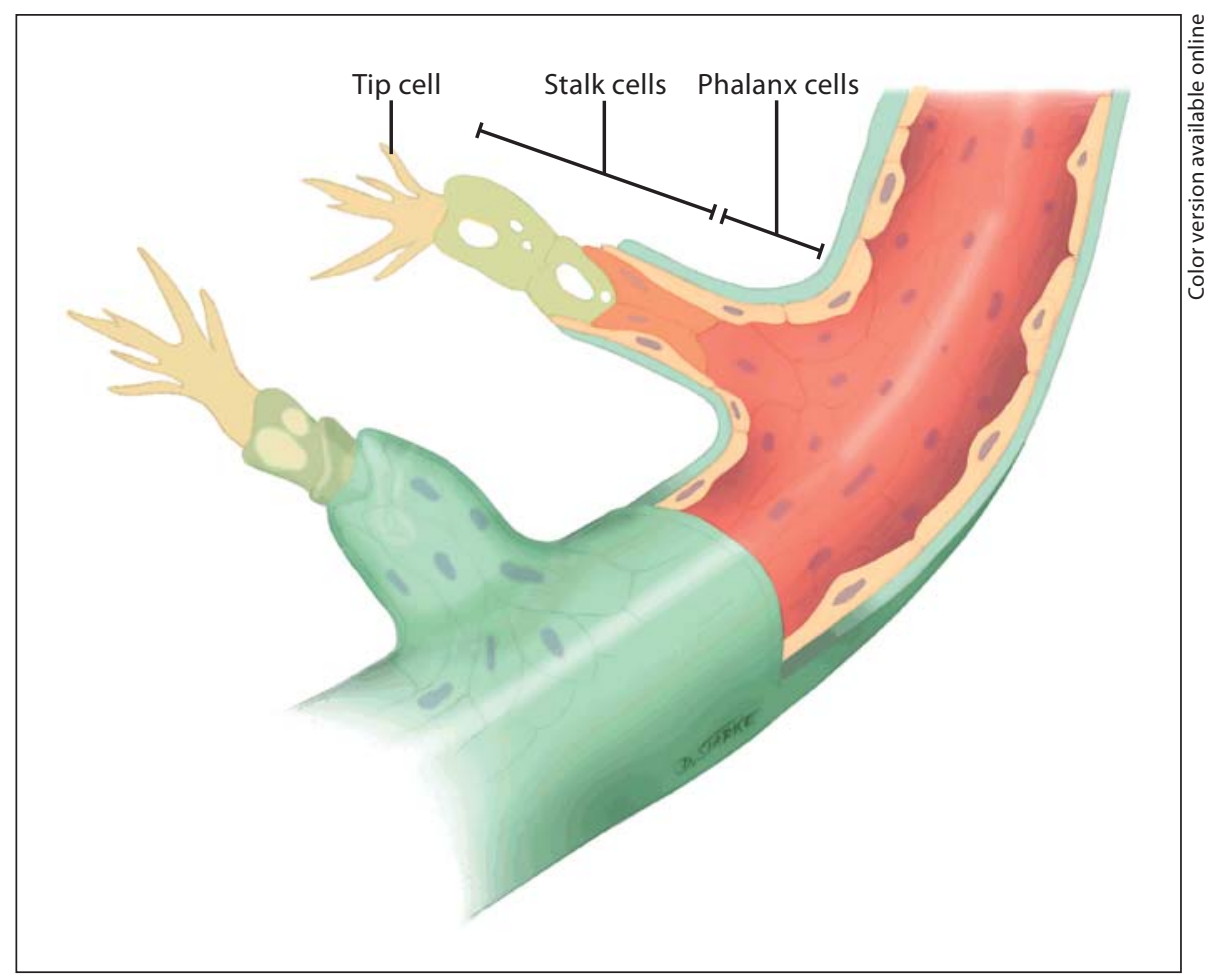

teins that are involved in the breakdown of the extracellular matrix, proteins that have a function in the construction of the basement membrane, and proteins that can regulate the trailing stalk cells in a paracrine fashion.

Stalk cells proliferate at a high rate, but they are not capable of moving to angiogenic stimuli as they lack high amounts of VEGFR2 and VEGFR3 on their cell membrane. Recently, Benedito et al. [27] demonstrated that expression of Jagged 1 in stalk cells partly inhibits the interaction of DLL4 with Notch so that the stalk cells remain partly responsive to VEGF, enabling them to proliferate but inhibiting them from transforming into tip cells $[20,27]$. Stalk cells start the process of lumenization and promote the formation of the capillary basement membrane [13]. Stalk cells are characterized by a high expression of the TIE2 receptor and the APJ receptors [26]. APJ is the receptor for apelin and has been observed to induce lumen formation downstream of the ANGPT1TIE2 pathway [28]. ANGPT1 and ANGPT2 are ligands of the TIE2 receptor. By activating TIE2, ANGPT1 induces vascular maturation as it tightens inter-endothelial junctions and induces migration of pericytes [29]. This action is inhibited by ANGPT 2 which competitively binds TIE2 but fails to activate the receptor [30, 31]. These interactions suggest that the ANGPT1/ANGPT2 balance trig- gers the switch from vascular maturation to further proliferation on the endothelial stalk cells.

Lumen formation is essential to allow a flow of blood through the new vessel. Five potential mechanisms have been described for lumen formation [32]: (1) wrapping, when a planar cell wraps itself to form a tube; (2) budding, when a tube-like structure sprouts out of a pre-existing tube; (3) cavitation, when a lumen is created in cell aggregates by apoptosis of the central cells; (4) cord hollowing, when a central lumen is formed in cell aggregates through changes in shape such as flattening of the cells, and (5) cell hollowing or vacuolation, when a lumen is formed inside an endothelial cell by an intracellular vacuole $[33,34]$. These different mechanisms of lumen formation seem to be tissue specific [32]. Vacuolation is most commonly observed, in vivo as well as in vitro. During vacuolation, pinocytic vesicles coalesce to form a large intracellular vacuole. Subsequently, these vacuoles coalesce with those of neighboring cells through an exocytotic event, leading to the formation of a lumen [32, 35]. Cord hollowing has been described in the developing aorta of mice, amphioxus, and zebrafish $[36,37]$, whereas cavitation has been described during lumenization of rat renal glomeruli [33].

Ultimately, the new vascular sprout needs to connect to neighboring sprouts or blood vessels in order to create 


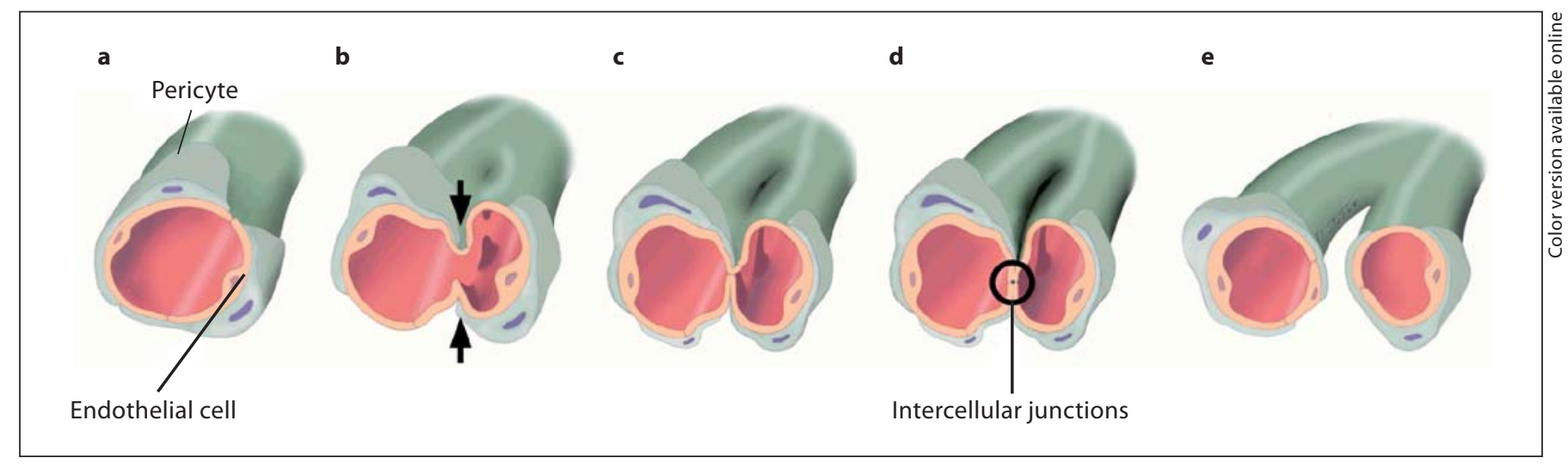

Fig. 2. Schematic illustration of a small capillary surrounded by pericytes (a) undergoing IA. The opposite walls of this capillary start to migrate to each other (b), an intraluminal pillar is formed (c), and the cellular junctions of the opposing endothelial cells are rearranged (d). Subsequently, further growth of the pillar leads to spitting of the blood vessel into two new vessels (e).

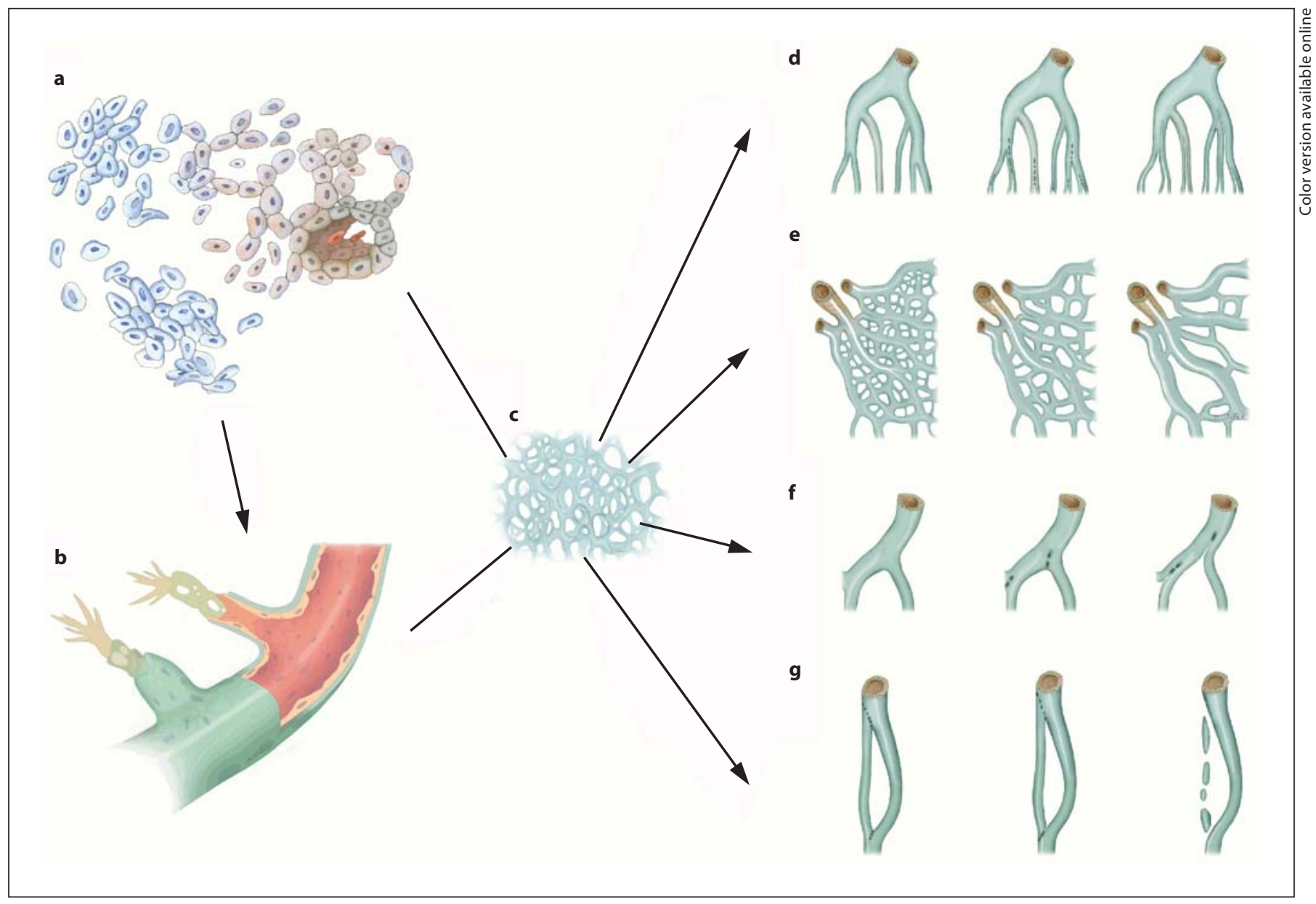

Fig. 3. Schematic illustration of the different forms of angiogenesis during development. Vasculogenesis (a) and SA (b) give rise to the formation of an immature vascular plexus (c) that further grows and remodels by the different forms of IA, i.e. IMG (d), IAR (e), IBR (f), and intussusceptive pruning (g). 
a continuous blood flow [38]. This item has received relatively little attention. However, recent work revealed that peculiar macrophages that express neuropilin 1 (NRP1) and TIE2 on their cell surface are crucial for the guidance and fusion of tip cells from two distinct sprouts. Experiments with mice lacking these specific macrophages revealed that tip cells are only able to migrate to an angiogenic stimulus but are unable to recognize other blood vessels or capillary sprouts [39].

\section{Intussusceptive Angiogenesis}

SA has been studied in great detail because it was recognized as the sole mechanism of angiogenesis for more than 170 years and because a whole range of in vitro and in vivo test systems have been developed to study this specific type of angiogenesis $[9,40]$. In contrast, IA, also called splitting angiogenesis or nonsprouting angiogenesis, was discovered in the late eighties of the 20th century and remains poorly investigated $[10,11,41]$. Nevertheless, IA seems to play a major role in the growth and remodeling of most vascular beds, including the vascular beds of tumors [12, 42, 43].

A typical characteristic of IA is the formation of socalled intraluminal tissue pillars that are formed by an invagination of the capillary walls into the vascular lumen $[11,44,45]$. The formation of intraluminal pillars proceeds through a multistep process [46]. It starts when the endothelial walls of the opposite sides of a vessel migrate to each other (fig. $2 a, b$ ), forming an intraluminal pillar (fig. 2c). The interendothelial junctions are reorganized (fig. 2c), and a central perforation is formed in the core of the pillar. Subsequently, this pillar is invaded by pericytes and myofibroblasts that deposit extracellular matrix into the pillar (fig. 2d). Finally, several pillars increase in size and fuse with each other, splitting up the initial capillary into two new capillaries (fig. 2e) [46].

\section{Morphological Characteristics of IA}

Three forms of IA are recognized, depending on the outcome or phenotype of these forms, i.e. intussusceptive microvascular growth (IMG), intussusceptive arborization (IAR), and intussusceptive branching remodeling (IBR) (fig. 3) [46]. IMG leads to the rapid expansion of an already existing vascular network through the continuous new formation and expansion of pillars into the network. This results in a simple network of similarly sized capillaries (fig. 3d). IMG is characterized by a diffuse appearance of numerous pillars. In a mechanism that is most likely driven by blood flow, these pillars fuse and split the vessels, expanding the capillary network and forming the organ-specific architecture [42]. In contrast, IAR contributes to the remodeling of a previously unhierarchical capillary network into a hierarchical vascular tree in which major arterioles, venules, and capillaries can be discerned. IAR can be recognized in a dense capillary network by the occurrence of a series of pillars, delineating the prospective supply vessel from the neighboring capillaries (fig. 3e). The third form of IA, IBR, can be defined as the mechanism that optimizes the number of vessels to efficiently supply a tissue with blood by either changing the branching pattern of blood vessels (fig. 3f) or pruning the vascular network from superfluous vessels (fig. 3g) [47]. IBR is commonly recognized by the occurrence of a tissue pillar close to the bifurcation of two blood vessels. These pillars enlarge and eventually merge with the perivascular connective tissue. As such, the bifurcation is further narrowed and the bifurcation point is relocated more proximally. In the case of pruning, pillars also appear close to a bifurcation, but they are situated more eccentrically and asymmetrically [48]. The elongation and fusion of these pillars cuts off the blood flow from the targeted blood vessel, which subsequently regresses.

\section{Occurrence of IA}

IA is a process that only occurs in a pre-existing vascular network that was formed either through vasculogenesis or through SA. In the majority of developing vascular beds, the initial network is formed through SA, and IA gradually takes over $[49,50]$. IA is a faster process than SA and it can occur without interfering with the local physiological conditions because no blind ending capillary segments are formed. The basement membrane remains intact during the course of IA, preventing the blood vessels from becoming leaky. In addition, endothelial migration and proliferation are kept to a minimum as the endothelial cells do not necessarily proliferate but rather increase in size and flatten $[51,52]$. This results in a relatively lower metabolic cost of IA in comparison with SA [47].

Since its discovery in developing lungs in the late eighties of the previous century, evidence for ongoing IA has been detected in a wide range of developing tissues such as bone, retina, muscle, kidney, ovary, mammary gland, and many more $[2,11,17,46,50,51,53,54]$. This data indicates that IA is actually a very common mechanism of blood vessel growth. Interestingly, investigations of different developmental stages in the mammary gland 
in developing glomeruli and in the cyclic ovary revealed that SA is predominant in the early stages of angiogenesis while IA predominates in the later stages of vascular growth and remodeling $[49,54,55]$. This suggests that the initial vascularization of growing tissues is mainly established through vasculogenesis or SA, and that the further remodeling is mainly performed by IA, as the latter process is quicker and is assumed to use less metabolic energy.

IA is also active in diverse pathologies and during tumor growth $[8,46]$. IA has been observed in different murine disease models, including models of liver cirrhosis, models of inflammation, and the hypoxic mouse retina [56-58]. In addition, IA was observed to start glomerular repair after induced Thy-1.1 nephritis in rats [59, 60]. IA has recently been observed to participate in tumor growth, such as in B-cell non-Hodgkin's lymphoma, in different types of gliomas, in mammary tumors, or during renal hepatocellular and colon carcinoma [55, 61-63]. Observations in mammary tumors of mice revealed that SA is active in small tumors (less than $8 \mathrm{~mm}$ in diameter), whereas IA is predominant in larger tumors [55]. Furthermore, recent evidence suggests that tumors respond with an angiogenic switch from SA to IA following ionizing radiation or antiangiogenic drug therapy using PTK787/ZK222584, a broad range tyrosine kinase inhibitor. These treatments are mainly designed to stop SA but lose their effect because the process of IA enables the vascular network to keep growing $[12,43,60]$. Consequently, future therapies will need to target both mechanisms of angiogenesis in order to be effective.

IA might also be exploited in proangiogenic therapy to re-establish a functional vascular plexus in ischemic tissues. This form of angiogenesis results in a faster and better organized vascular plexus in comparison to SA. Current proangiogenic therapies mainly aim to induce SA, leading to the accumulation of fluid and transient edema in tissues [64]. This might be due to the leaky nature of newly formed vascular sprouts during SA. The specific induction of IA after an initial colonization of angiogenic sprouts into the ischemic tissue could enhance vascular normalization, improving the therapeutic outcome. These proangiogenic therapies could be used in various forms of ischemic disease including ischemic heart diseases, large wound healing, and atherosclerosis [64].

Altogether, this data emphasizes the need for thorough comprehension of the molecular pathways regulating IA. However, research on these molecular pathways is hampered by the limited availability of experimental models and analytical tools to study IA [10]. This is due to the difficulty to induce and visualize IA both in vivo and in vitro.

\section{Regulation of IA}

Hemodynamic forces play an important role during the process of IA [47]. Blood flow has been observed to establish a hierarchical vasculature with venules and arterioles from a pre-existing capillary plexus in the chick chorioallantoic membrane (CAM) [65, 66]. Experiments using the chick CAM revealed an increase in IA in blood vessels in which the blood flow is enhanced by clamping their side branches $[44,47]$. Interestingly, in 1939 the remodeling of a vascular plexus after an experimentally induced increased blood flow was already observed to occur through the formation of small vessel loops, but this network remodeling was not recognized as IA [42, 67]. It is still unclear whether the effect of hemodynamics on IA is mainly induced by changes in hydrostatic pressure, by cyclic stretch, by shear stress, or by a combination of all of the previous factors [52]. Shear stress seems to play a major role, since in silico models revealed that tissue pillars occur in places with low shear stress caused by turbulence due to an increased blood flow $[47,52,68]$.

Apart from the hemodynamic forces, IA is also regulated by molecular actors. However, due to lack of appropriate experimental assays, only scarce data are available on the molecular control of IA. Consequently, there are mainly indirect indications about the possible roles of some molecules during IA.

VEGF is the best described angiogenic growth factor, but few data exist on the function of VEGF during IA [69]. Initial work in developing chick glomeruli and in the chicken embryonic lung indicated that VEGF mainly affects SA and that it is downregulated in vascular beds that are growing by IA $[49,70]$. This indicates that factors other than VEGF might be involved in IA. However, recent investigations on the chick CAM and observations in human gliomas suggest that VEGF and VEGF isoforms play an important but unclear role during IA [48, 63, 71]. A decrease in VEGF levels after depletion of VEGF releasing hydrogels on the growing chick CAM is associated with a reduction of the vascular network through intussusceptive vascular pruning [48]. Recent data indicate that a different expression of the VEGF receptors might determine the angiogenic phenotype. A study of the gene expression in developing glomeruli revealed upregulation of VEGFR2 in early glomerular development but a significant downregulation of this receptor in later devel- 
opment when glomeruli were still growing [50]. In addition, glomerular repair through IA is not readily halted afteraddition of a VEGFR2 inhibitor(PTK787/ZK222584) [60]. This might suggest that VEGFR2 is mainly important for SA, being the main mechanism in early glomerular growth, and that other receptors for VEGF (e.g. VEGFR1) might be more important for IA which predominates in late glomerular growth $[49,50]$. Better insight into the expression of specific VEGF isoforms and of their receptors during IA might clarify the role of VEGF during IA and SA.

Apart from VEGF, the angiopoietins are also important angiogenic growth factors, and there are clear indications that these factors play an important role during IA $[10,72]$. Targeted deletion of TIE2 expression in mice leads to deficient pillar formation [73]. ANGPT1-overexpressing mice show a vascular phenotype of enlarged vessels with abundant small invaginations that are reminiscent of the intraluminal pillars encountered during IA $[41,74,75]$. Both ANGPT1 and ANGPT2 are continuously expressed in growing kidney glomeruli [50, 76]. Moreover, overexpression of ANGPT2 affects ongoing IA in the chick CAM as it leads to remodeling of a previously uniform capillary mesh into an arborized vascular tree [77].

Studies on the developing chick vasculature also indicated that fibroblast growth factor (FGF2) and PDGFB might play a regulatory role during IA $[49,70]$. In the developing chick mesonephros, increased FGF2 expression in podocytes was correlated with a phenotypic switch from SA to IA [49]. The function of FGF2 during IA is still elusive. Expression of FGF2 induces PDGF receptor expression in newly formed blood vessels. PDGFB is important for pericyte recruitment [78] and, since pericytes play a role in the formation of tissue pillars, it might be hypothesized that FGF2 regulates IA by inducing PDGFB responsiveness in pericytes through upregulation of the PDGF receptors $[42,44]$. However, recent investigations on the angiogenesis inhibitor (PTK787/ZK222584) revealed that IA is only inhibited after 14 days of treatment, suggesting that this type of angiogenesis might be regulated by additional factors [60].

Recently, IA was observed to be upregulated in response to hypoxia with a chronic hypoxia model in mice [79]. Hypoxia can trigger the expression of several angiogenic genes through upregulation of hypoxia-inducible factors [80]. As an example, hypoxia-inducible factor 2 alpha (HIF2 $\alpha$ ) upregulates erythropoietin (EPO) expression [81, 82]. EPO has been described as a possible regulator of IA, as addition of EPO to the chick CAM enhanced IMG [83]. In addition, EPO was observed to be expressed in blood vessels undergoing IA in human glioma tumors [84].

Because of the current scarcity of experimental and descriptive studies on IA, it can be expected that additional angiogenic factors might also influence the process of IA. The most likely candidates might be factors that regulate EC-pericyte interactions and cell-cell junctions. Among the factors regulating cell-cell interactions, VEcadherin might be an interesting candidate since deletion of this factor in mice leads to a disturbed morphogenesis of developing blood vessels $[9,85]$. In addition, the ephrins and the eph-B receptor or monocyte chemotactic protein 1 have also been proposed as other potential regulators of IA $[46,72]$.

\section{Descriptive Methods to Study IA}

\section{Vascular Corrosion Casting}

The process of IA was first discovered on the basis of scanning electron microscopy (SEM) with vascular corrosion casts [11]. This enables the identification of intraluminal pillars that become evident as small holes with a diameter of 1-2 $\mu \mathrm{m}$ through the cast capillary lumen (fig. 4). The analysis of corrosion casts with SEM provides a good approach for screening various tissues for the presence of IA. However, only the external surface of the corrosion casts can be monitored. This drawback was recently overcome by scanning casts with an in-house-developed high-resolution micro computerized tomography (micro-CT) system [50, 86]. In contrast to most commercial systems, this high-resolution micro-CT provides a resolution of $1 \mu \mathrm{m}$, just precise enough to recognize intraluminal pillars [50]. The major drawback of vascular corrosion casting is that it can only be used for end-stage evaluation of the angiogenic morphology.

\section{Serial Sections}

Light microscopic or transmission electron microscopic observations of serial semithin $(1 \mu \mathrm{m})$ or ultrathin $( \pm 60$ $\mathrm{nm})$ sections provide the most appropriate technique to unambiguously confirm the presence of intraluminal pillars. With this method, the intraluminal pillars can be visualized by the subsequent appearance and disappearance of the pillar [44]. This technique provides the possibility to investigate the fine morphological changes during the process of pillar formation (fig. 5-7). However, this method is laborious and the recognition of pillar formation in complex vascular beds is very challenging, making it unsuitable for large-scale screening of blood vessels. 



Fig. 4. Scanning electron micrographs of corrosion casts of the growing vasculature in the porcine neonatal mandibular (a) and frontal (b) bone. Intraluminal pillars can be observed as small holes through the casts (arrowheads). Scale bar $=100 \mu \mathrm{m}$.



a

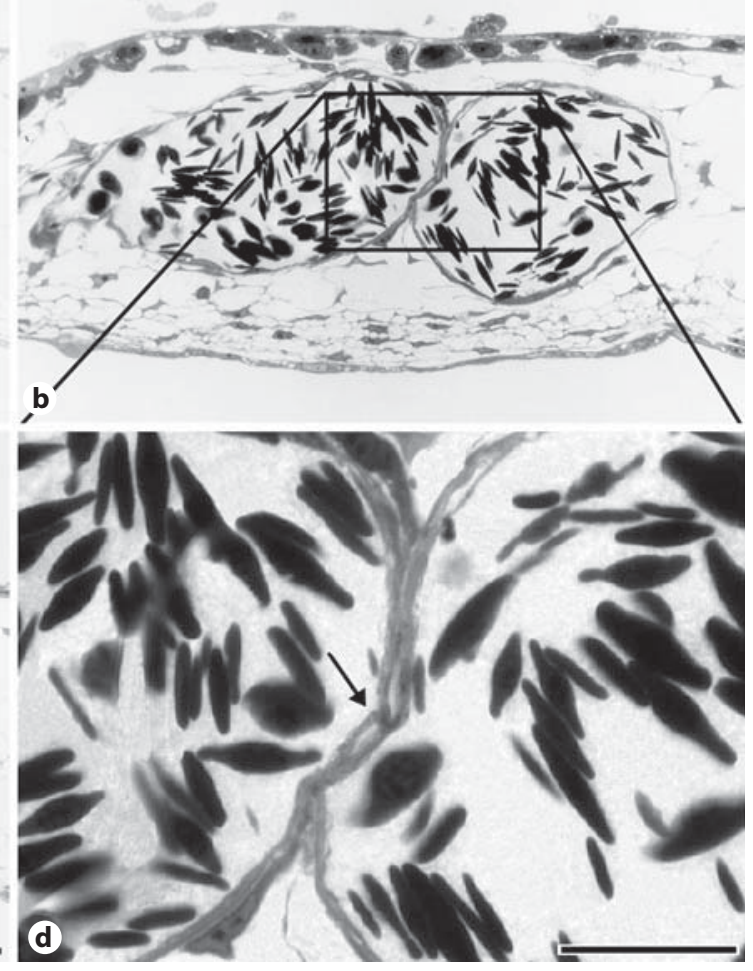

Fig. 5. Lightmicroscopic micrographs of serial semithin sections through an intraluminal pillar during the process of IMG showing a section just next to a tissue pillar (a), through a pillar (b), and on the other side of the pillar (c). The black arrow in $\mathbf{d}$ points to an intercellular junction between the two endothelial layers. Scale bar $=80 \mu \mathrm{m}(\mathbf{a}-\mathbf{c})$ and $40 \mu \mathrm{m}(\mathbf{d})$. Adapted from Djonov et al. [47]. 


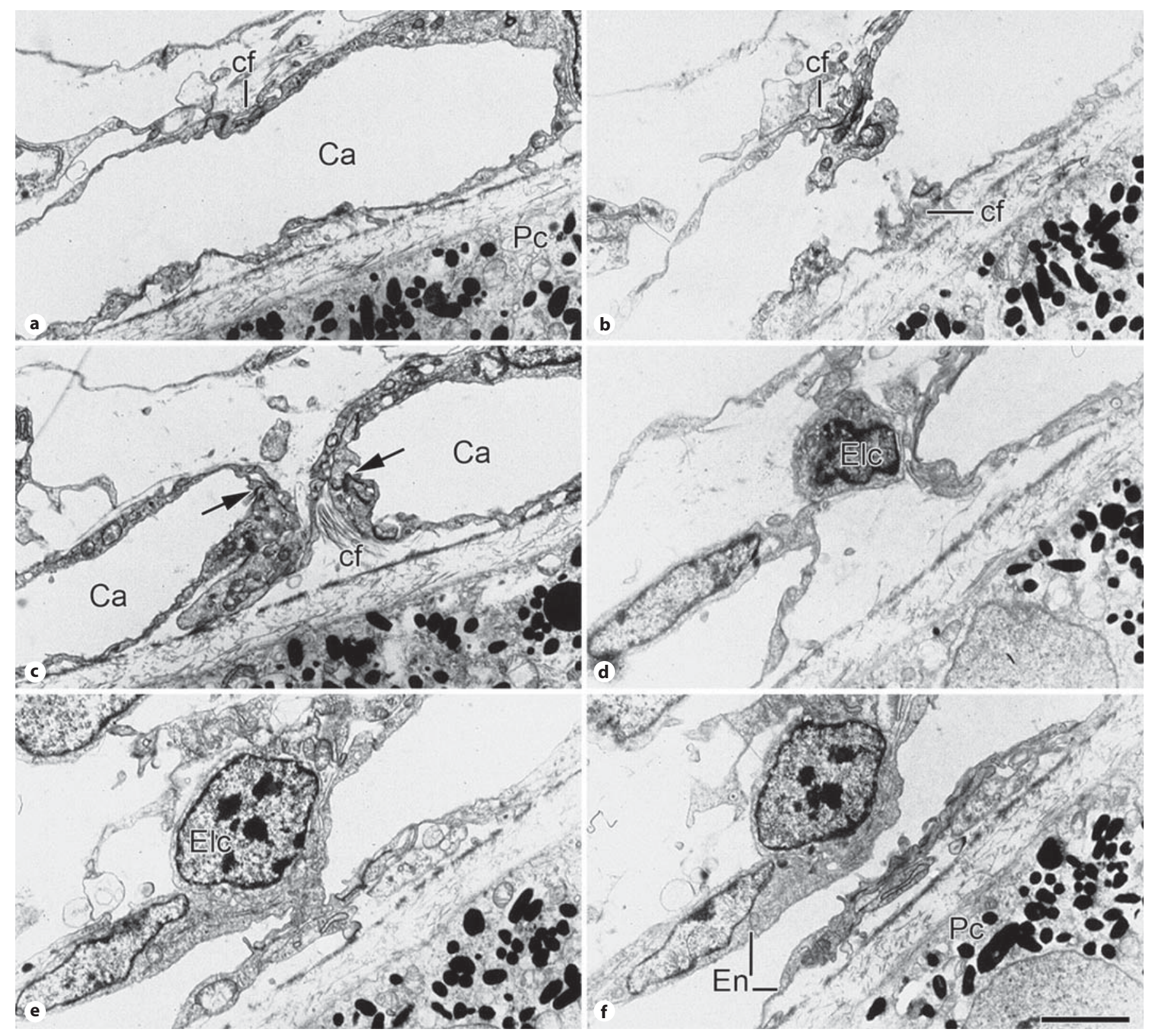

Fig. 6. Transmission electron microscopic micrographs of ultrathin sections through an intraluminal pillar $(\mathbf{a}-\mathbf{f})$; a pillar is formed with collagen fibers within its core ( $\mathrm{cf}$ in $\mathbf{b})$, and interendothelial junctions are visible (arrows in c). The nucleus of an endothelial-like cell (ELC) is positioned between the capillary walls (d, e). Scale bar $=2 \mu \mathrm{m}$. En = Endothelium; $\mathrm{Pc}=$ pigment; $\mathrm{Ca}=$ capillary lumen. Adapted from Djonov et al. [44].

\section{Confocal Laser Scanning Microscopy}

IA can also be observed by confocal laser scanning microscopy (CLSM) on tissue sections stained with immunofluorescent endothelial cell markers [87]. Using this approach, three-dimensional images can be obtained from intraluminal pillars, and double labeling with specific en- dothelial cell markers together with pericyte markers might provide more insight into the function of these cells in the formation of intraluminal pillars [12]. Moreover, CLSM can also be used to investigate the precise localization of certain growth factors and cell membrane-bound proteins around the growing tissue pillar. Recently, a 
method was optimized to visualize capillaries without using EC-specific antibodies but rather using lipophilic carbocyanine dyes, making the process of fluorescent blood vessel labeling much easier [88]. CLSM has also been combined with vascular corrosion casts to which a fluorescent dye was added [89]. With this technique, the surrounding tissue can remain intact, enabling microscopic observation of the surrounding endothelial cells and pericytes.

\section{In vivo Microscopic Video Analysis}

In certain tissues, such as in the chick CAM, the process of IA might also be analyzed in real time using in vivo microscopic video analysis. By injecting a fluorescent dye into the vasculature, the morphogenesis of the capillaries of the chick CAM can be monitored, and the formation of intraluminal pillars can be detected near the bifurcation points of capillaries [47] (fig. 7b, c). This method is specifically suitable for monitoring intraluminal pillar formation in real time. It might also be used in other vascular beds, but these should be easily accessible, without need for dissection procedures interfering with the angiogenic process.

\section{Experimental Models to Study IA}

While descriptive studies may provide more hypotheses on the process of IA, experimental models are crucial to gain evidence for these postulates. A plethora of in vitro and in vivo angiogenesis models has been described during the past decades. However, most models are only optimized to study SA or do not enable discernment of sprouting from IA $[40,90,91]$.

The ideal experimental model for angiogenesis should provide a good mimic of the process under study [40]. In addition, it should be highly reproducible, it should provide the possibility to monitor the process of angiogenesis in real time without inducing extra environmental bias, and it should enable the possibility to carefully monitor and adjust the concentration of angiogenic factors in a spatial and temporal fashion $[90,91]$. Unfortunately, no such model has been developed to date. In vitro models provide the possibility to monitor the concentration of all angiogenic factors and the process of angiogenesis in real time without interfering with the ongoing angiogenesis. However, the conditions in these in vitro models are highly different from in vivo conditions. This hampers the extrapolation of experimental results from an in vitro context to the in vivo situation [90]. In vivo models provide an interesting alternative as
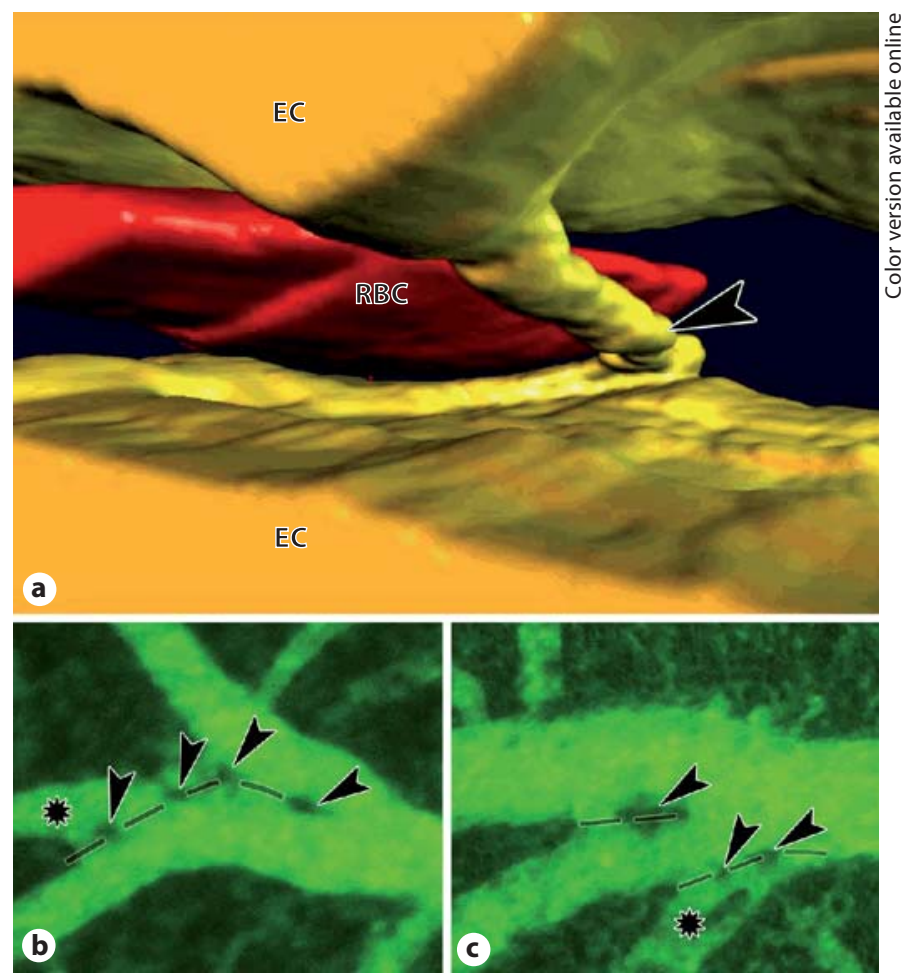

Fig. 7. a Three-dimensional reconstruction of transmission electronic micrographs from serial ultrathin sections through a tissue pillar showing the endothelial cells (EC), the intraluminal pillar (arrowhead), and a red blood cell (RBC) within the capillary lumen. b, c Fluorescent micrograph of the formation of an intraluminal pillar formation during intussusceptive pruning happening in the chick CAM in real time; the pillars (arrowheads) are formed at the basis of the capillary that will be disconnected from the blood flow (star). Adapted from Djonov et al. [44] and Hlushchuk et al. [48].

the process of angiogenesis in these models occurs in natural physiological conditions. However, in vivo models are highly complex and the concentrations of angiogenic factors and other environmental factors cannot be easily monitored and adjusted. Moreover, realtime monitoring of the angiogenic process at high resolution is almost impossible in in vivo models [40,90]. As a result, most studies rely on a combination of in vitro and in vivo models.

\section{In vivo}

The occurrence of IA can be monitored in most in vivo angiogenesis models using the vascular corrosion casting technique. Unfortunately, vascular corrosion casting is not regularly used in most angiogenic investigations, and 
a thorough screening for the phenotype of the angiogenic mechanism is hardly performed.

Recently, IA was reported to occur in the retina of mice that were raised in hypoxic conditions [79]. This chronic hypoxia model is often used to study retinal angiogenesis and might also form an interesting model for studying IA. Kidney glomeruli are also interesting candidates to study this mechanism of angiogenesis. These vascular beds are already used as models of angiogenic repair through IA $[59,60]$. During their development, growing glomeruli display a remarkable switch of the angiogenic phenotype from SA to IA $[49,50]$. In the rat arteriovenous loop model, an arteriovenous fistula (loop) is constructed from the femoral neurovascular bundle and embedded in a fibrin matrix within a Teflon isolation chamber [92]. This procedure combined with corrosion casting and SEM allows quantitative investigation of the influence of angiogenic growth factors on the angiogenic phenotype including intussusceptive pillar formation. The above in vivo models are promising tools to study the molecular pathways regulating IA. However, they only allow evaluation of the capillaries after sacrificing the animals and they do not allow evaluation of the process of IA in real time.

The chick CAM assay is the only model that was recently developed to study IA in real time $[44,71,77]$ and ranks among the most frequently used angiogenesis assays $[40,91]$. It consists of a remodeling two-dimensional capillary bed that can be monitored in real time with a fluorescent microscope after injection of a fluorescent dye into the circulation of the growing embryo. In this way, the process of pillar formation at the bifurcation point of splitting vessels can be demonstrated [44], and the influence of various pro- and antiangiogenic substances can be evaluated $[71,77]$. The major drawback of this assay is the fact that it is only applicable with bird species which are phylogenetically more distant from humans than the species used in mammalian models. Moreover, the chick CAM microvasculature is already angiogenically highly active by itself, and this might interfere with experimental results [40,93].

In vitro

To date, only two in vitro models have been reported to show some characteristics of IA $[94,95]$. Hirschberg et al. [95] performed an ultrastructural investigation of an in vitro angiogenesis model in which endothelial cells form a capillary-like network without being imbedded in an exogenous extracellular matrix $[40,96]$. SEM observations of the process of angiogenesis in these cell cultures reveal that cellular strands form a complex network

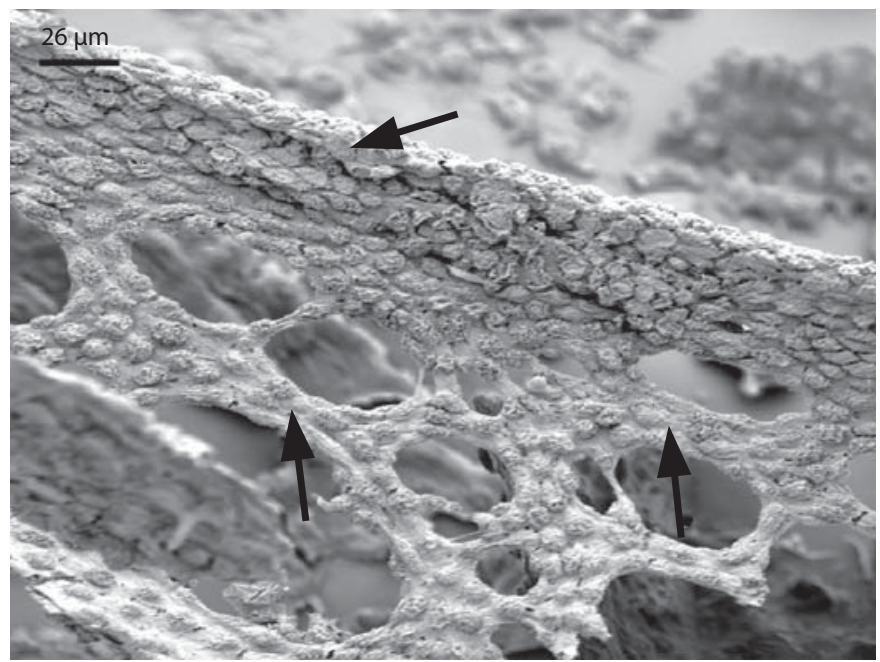

Fig. 8. Scanning electron micrographs of endothelial cells in culture. A three-dimensional network of capillary-like (arrows) structures is apparent.

through the expansion of gaps in the cell strands (fig. 8). This process of network formation is reminiscent of the process of IA, but further ultrastructural analysis should better characterize this process of in vitro network formation. In the model of Levin et al. [94], endothelial cells are seeded at a high density on a pre-established monolayer of smooth muscle cells. The endothelial cells form a monolayer on top of the smooth muscle cells and are separated from each other by a basement membrane, mimicking the vascular wall of blood vessels in vivo. Subsequently, the endothelial cell wall starts to fold and to procure intravascular pillars. These pillars do not possess a lumen but contain components of the extracellular matrix and basement membranes, similar to intraluminal pillars formed during IA. Although this seems a promising in vitro model of pillar formation, these pillars should be further characterized as it is still questionable whether these pillars are effectively similar to the intraluminal pillars that are observed during IA [94].

An additional drawback of the present in vitro models of IA is the lack of experimentally induced blood flow at the capillary level. Since IA is a blood flow-mediated mechanism of vessel remodeling, experimentally induced blood flow in vitro will result in angiogenic models that better represent the in vivo situation. Many in vitro models mimicking blood flow in tubes with varying diameters exist [97], but these tubes are synthetic and do not allow organic reorganization of the endothelial cells and capillaries. 


\section{In silico Models}

Mathematical models are increasingly used in life science. These models permit the interpretation of highly complex systems in which multiple factors are influential, enabling a holistic approach to investigating biological systems $[98,99]$. In the past decades, some in silico models have been optimized to study the process of IA. The current models are based on the chick chorioallantoic model as this model allows relatively easy verification of the in silico data in the in vivo system when compared to other in vivo models of angiogenesis [52]. Initially, the in silico models were merely based on the formation of bifurcations [100], but later models also included the formation of intraluminal pillars $[68,101,102]$. Because the models are all strictly based on studying hemodynamic forces, Szczerba et al. [103] developed a more realistic model for IA in which biochemical factors may also be incorporated and in which multiple cell layers, not merely the vascular wall, are taken into account. This model may be used as a first in silico step to test various hypotheses prior to more laborious in vitro and in vivo tests. These experiments will in turn provide extra information to further optimize the current in silico models and vice versa $[52,103]$. In addition, these models might be combined with other theoretical models of vascular remodeling that have been described in the past $[65,66,104]$.

\section{Vascular Cooption and Vascular Mimicry}

Apart from SA and IA, two other forms of angiogenesis have recently been described, i.e. vascular cooption and vascular mimicry. However, to date, these forms have only been detected in developing tumors and will not be discussed in great detail in this review.

\section{Vascular Cooption}

In highly vascularized tissues, tumors can grow to a certain extent without eliciting a specific angiogenic response by parasitizing on the pre-existing vasculature of the tissue in which the tumors grow [8]. This has been observed in human melanoma tumors that were introduced in mice brain parenchyma $[105,106]$. Instead of eliciting an angiogenic response, the tumors associate with the pre-existing host vessels, and as the tumors increase in size, the blood vessels become completely embedded in the tumor [105]. However, after a period of time, the co-opted vessels in these tumors start to regress because of an elevated ANGPT2 expression resulting from a host defense mechanism $[8,106]$. Consequently, vascular cooption is mainly observed during initial tumor growth. The subsequent regression of the co-opted vessel elicits a robust angiogenic response and new blood vessels enter the tumor via SA or IA or through vascular mimicry [8].

Recently, a mechanism similar to vascular cooption was described in healing wound tissues whereby myofibroblasts pull nearby blood vessels into the injured area, thereby allowing the recruitment of mature vessels that can trigger a quick start to vascular remodeling and the reconstitution of a functional vascular network in the injured tissue [107].

\section{Vascular Mimicry}

In certain tumors, the tumor cells can take over an endothelial phenotype and can form a capillary-like network on their own [108]. This process of vascular mimicry results in a capillary network completely composed of tumor cells rather than vascular endothelial cells. This was described for the first time by Maniotis et al. [109]. Vascular mimicry might also lead to mosaic vessels that are characterized by alternating tumoral and endothelial cells in the capillary walls [110].

Vascular mimicry is mainly detected in aggressive tumors including melanomas, renal cell carcinoma, Ewing sarcoma, and breast, ovarian, prostate, and lung tumors $[108,109]$. In aggressive melanomas, the tumor cells exhibiting an endothelial phenotype were observed to genetically reverse from an aggressive melanoma type to an endothelial-like phenotype in which endothelial specific genes are upregulated [111]. This suggests that vascular mimicry closely resembles and recapitulates vasculogenesis which is mainly observed in the growing embryo, except that vascular mimicry starts from dedifferentiated tumor cells whereas vasculogenesis starts with endothelial progenitor cells $[108,112]$. The occurrence of vascular mimicry may complicate the use of antiangiogenic strategies to treat certain tumors, as the loss of one type of angiogenesis due to therapy might be compensated by a phenotypic switch to another mechanism of angiogenesis [8].

\section{Conclusions}

The growth and remodeling of blood vessels is a complex process that proceeds through different mechanisms of angiogenesis. Proper knowledge of these distinct mechanisms will enhance our understanding of angiogenesis and aid in the development of more efficient strat- 
egies for future pro- or antiangiogenic therapies. SA is being extensively studied, and some therapeutics are already used in anticancer therapies. However, the existence of alternative processes of angiogenesis may render these specific therapies inefficient. In addition, SA is only responsible for vascular growth, but not for vessel pruning or for the remodeling of capillary beds. Thorough knowledge of IA could also help proangiogenic therapy since this form of angiogenesis is both faster and more efficient than SA. Inducing this form of angiogenesis may improve therapeutic revascularization strategies in ischemic tissues.

IA is now viewed as a very general mechanism of blood vessel remodeling that takes place in a great variety of developing organs, as well as during pathological angio- genesis. Better knowledge of the mechanism of IA is thus urgent and may revolutionize the current research on angiogenesis. However, investigations on IA are only performed by a few researchers worldwide. Future studies should pay more attention to the angiogenic phenotype in in vivo models since the vascular phenotype is often overlooked in angiogenic experiments. In addition, more and better in vivo and in vitro models are needed to study the molecular pathways regulating IA.

\section{Acknowledgment}

The authors wish to thank Diemut Starke (Institute for Veterinary Anatomy, Berlin) for the drawings.

\section{References}

$>1$ Griffioen AW, Molema G: Angiogenesis: Potentials for pharmacologic intervention in the treatment of cancer, cardiovascular diseases, and chronic inflammation. Pharmacol Rev 2000;52:237-268.

$\checkmark 2$ Andres AC, Djonov V: The mammary gland vasculature revisited. J Mammary Gland Biol Neoplasia 2010;15:319-328.

3 Ferrara N, Alitalo K: Clinical applications of angiogenic growth factors and their inhibitors. Nat Med 1999;5:1359-1364.

$\checkmark 4$ Carmeliet P: Angiogenesis in life, disease and medicine. Nature 2005;438:932-6.

$\checkmark 5$ Paleolog EM: The vasculature in rheumatoid arthritis: cause or consequence? Int J Exp Pathol 2009;90:249-261.

$\checkmark 6$ Ribatti D: Judah Folkman, a pioneer in the study of angiogenesis. Angiogenesis 2008;11: 3-10.

7 Potente M, Gerhardt H, Carmeliet P: Basic and therapeutic aspects of angiogenesis. Cell 2011;146:873-887.

$>8$ Hillen F, Griffioen AW: Tumour vascularization: sprouting angiogenesis and beyond. Cancer Metastasis Rev 2007;26:489-502.

$\checkmark 9$ Carmeliet P, Jain RK: Molecular mechanisms and clinical applications of angiogen esis. Nature 2011;473:298-307.

10 Augustin HG: Tubes, branches, and pillars: the many ways of forming a new vasculature. Circ Res 2001;89:645-647.

$\checkmark 11$ Caduff JH, Fischer LC, Burri PH: Scanning electron-microscope study of the developing microvasculature in the postnatal rat lung. Anat Rec 1986;216:154-164.

12 Hlushchuk R, Riesterer O, Baum O, Wood J, Gruber G, Pruschy M, Djonov V: Tumor recovery by angiogenic switch from sprouting to intussusceptive angiogenesis after treatment with PTK787/ZK222584 or ionizing radiation. Anticancer Res 2008;28:166.
13 De Smet F, Segura I, De Bock K, Hohensinner PJ, Carmeliet P: Mechanisms of vessel branching filopodia on endothelial tip cells lead the way. Arterioscler Thromb Vasc Biol 2009;29:639-649.

14 Carmeliet P: Mechanisms of angiogenesis and arteriogenesis. Nat Med 2000;6:389395.

15 Bouis D, Kusumanto Y, Meijer C, Mulder $\mathrm{NH}$, Hospers GA: A review on pro- and antiangiogenic factors as targets of clinical intervention. Pharmacol Res 2006;53:89-103.

16 Armulik A, Genov G, Betsholtz C: Pericytes: developmental, physiological, and pathological perspectives, problems, and promises. Dev Cell 2011;21:193-215.

17 De Spiegelaere W, Cornillie P, Casteleyn C, Burvenich C, Van den Broeck W: Detection of hypoxia inducible factors and angiogenic growth factors during foetal endochondral and intramembranous ossification. Anat Histol Embryol 2010;39:376-384.

18 Jakobsson L, Bentley K, Gerhardt H: VEGFRs and Notch: a dynamic collaboration in vascular patterning. Biochem Soc Trans 2009;37:1233-1236.

19 Gerhardt H, Golding M, Fruttiger M, Ruhrberg C, Lundkvist A, Abramsson A, Jeltsch M, Mitchell C, Alitalo K, Shima D, Betsholtz $\mathrm{C}$ : VEGF guides angiogenic sprouting utilizing endothelial tip cell filopodia. J Cell Biol 2003;161:1163-1177.

20 Kume T: Novel insights into the differential function of Notch ligands in vascular formation. J Angiogenes Res 2009;1:8.

21 Eilken HM, Adams RH: Dynamics of endothelial cell behavior in sprouting angiogenesis. Curr Opin Cell Biol 2010;22:617-625.
22 Mazzone M, Dettori D, de Oliveira R, Loges S, Schmidt T, Jonckx B, Tian YM, Lanahan A, Pollard P, de Almodovar C, De Smet F, Vinckier S, Aragons J, Debackere K, Luttun A, Wyns S, Jordan B, Pisacane A, Gallez B, Lampugnani M, Dejana E, Simons M, Ratcliffe P, Maxwell P, Carmeliet P: Heterozygous deficiency of PHD2 restores tumor oxygenation and inhibits metastasis via endothelial normalization. Cell 2009;136: 839-851.

23 Lawson ND, Weinstein BM: Arteries and veins: Making a difference with zebrafish. Nat Rev Genet 2002;3:674-682.

24 Suchting S, Freitas C, le Noble F, Benedito R, Breant C, Duarte A, Eichmann A: The Notch ligand Delta-like 4 negatively regulates endothelial tip cell formation and vessel branching. Proc Natl Acad Sci USA 2007; 104:3225-3230.

25 Roca C, Adams RH: Regulation of vascular morphogenesis by Notch signaling. Genes Dev 2007;21:2511-2524.

-26 del Toro R, Prahst C, Mathivet T, Siegfried G, Kaminker JS, Larrivee B, Breant C, Duarte A, Takakura N, Fukamizu A, Penninger J, Eichmann A: Identification and functional analysis of endothelial tip cell-enriched genes. Blood 2010;116:4025-4033.

-27 Benedito R, Roca C, Sorensen I, Adams S, Gossler A, Fruttiger M, Adams RH: The notch ligands Dll4 and Jagged1 have opposing effects on angiogenesis. Cell 2009;137: 1124-1135.

-28 Kidoya H, Ueno M, Yamada Y, Mochizuki N, Nakata M, Yano T, Fujii R, Takakura N: Spatial and temporal role of the apelin/APJ system in the caliber size regulation of blood vessels during angiogenesis. EMBO J 2008; 27:522-534. 
29 Saharinen P, Bry M, Alitalo K: How do angiopoietins Tie in with vascular endothelial growth factors? Curr Opin Hematol 2010;17: 198-205.

-30 Fukuhara S, Sako K, Noda K, Zhang J, Minami M, Mochizuki N: Angiopoietin-1/Tie2 receptor signaling in vascular quiescence and angiogenesis. Histol Histopathol 2010; 25:387-396.

- 31 Maisonpierre PC, Suri C, Jones PF, Bartunkova S, Wiegand S, Radziejewski C, Compton D, McClain J, Aldrich TH, Papadopoulos N, Daly TJ, Davis S, Sato TN, Yancopoulos GD: Angiopoietin-2, a natural antagonist for Tie2 that disrupts in vivo angiogenesis. Science 1997;277:55-60.

- 32 Iruela-Arispe ML, Davis GE: Cellular and molecular mechanisms of vascular lumen formation. Dev Cell 2009;16:222-231.

- 33 Fierlbeck W, Liu A, Coyle R, Ballermann B: Endothelial cell apoptosis during glomerular capillary lumen formation in vivo. J Am Soc Nephrol 2003;14:1349-1354.

34 Lubarsky B, Krasnow MA: Tube morphogenesis: making and shaping biological tubes. Cell 2003;112:19-28.

- 35 Adams RH, Alitalo K: Molecular regulation of angiogenesis and lymphangiogenesis. Nat Rev Mol Cell Biol 2007;8:464-478.

- 36 Strilic B, Kucera T, Eglinger J, Hughes MR, McNagny KM, Tsukita S, Dejana E, Ferrara $\mathrm{N}$, Lammert E: The molecular basis of vascular lumen formation in the developing mouse aorta. Dev Cell 2009;17:505-515.

-37 Ellertsdotir E, Lenard A, Blum Y, Krudewig A, Herwig L, Affolter M, Belting HG: Vascular morphogenesis in the zebrafish embryo. Dev Biol 2010;341:56-65.

- 38 Schmidt T, Carmeliet P: Blood-vessel formation: bridges that guide and unite. Nature 2010;465:697-699.

- 39 Fantin A, Vieira J, Gestri G, Denti L, Schwarz Q, Prykhozhij S, Peri F, Wilson S, Ruhrberg C: Tissue macrophages act as cellular chaperones for vascular anastomosis downstream of VEGF-mediated endothelial tip cell induction. Blood 2010;116:829-840.

-40 Bahramsoltani M, Plendl J, Janczyk P, Custodis P, Kässmeyer S: Quantitation of angiogenesis and antiangiogenesis in vivo, ex vivo and in vitro: an overview. ALTEX 2009;26: 95-107.

-41 Burri PH, Tarek MR: A novel mechanism of capillary growth in the rat pulmonary microcirculation. Anat Rec 1990;228:35-45.

-42 Makanya AN, Hlushchuk R, Djonov VG: Intussusceptive angiogenesis and its role in vascular morphogenesis, patterning, and remodeling. Angiogenesis 2009;12:113-123.

43 Hlushchuk R, Makanya A, Djonov V: Escape mechanisms after antiangiogenic treatment, or why are the tumors growing again? Int J Dev Biol 2011;55:563-567.

-44 Djonov V, Schmid M, Tschanz SA, Burri PH: Intussusceptive angiogenesis: its role in embryonic vascular network formation. Circ Res 2000;86:286-292.
45 Djonov V, Baum O, Burri P: Vascular remodeling by intussusceptive angiogenesis. Cell Tissue Res 2003;314:107-117.

46 Burri PH, Djonov V: Intussusceptive angiogenesis: the alternative to capillary sprouting. Mol Aspects Med 2002;23:S1-S27.

47 Djonov VG, Kurz H, Burri PH: Optimality in the developing vascular system: branching remodeling by means of intussusception as an efficient adaptation mechanism. Dev Dyn 2002;224:391-402.

48 Hlushchuk R, Ehrbar M, Reichmuth P, Heinimann N, Styp-Rekowska B, Escher R, Baum O, Lienemann P, Makanya A, Keshet E, Djonov V: Decrease in VEGF expression induces intussusceptive vascular pruning. Arterioscler Thromb Vasc Biol 2011;31: 2836-2844.

-49 Makanya AN, Stauffer D, Ribatti D, Burri PH, Djonov V: Microvascular growth, development, and remodeling in the embryonic avian kidney: the interplay between sprouting and intussusceptive angiogenic mechanisms. Microsc Res Tech 2005;66:275-288.

50 De Spiegelaere W, Cornillie P, Erkens T, Van Loo D, Casteleyn C, Van Poucke M, Burvenich C, Van Hoorebeke L, Van Ginneken C, Peelman L, Van den Broeck W: Expression and localization of angiogenic growth factors in developing porcine mesonephric glomeruli. J Histochem Cytochem 2010;58: 1045-1056.

51 Egginton S, Zhou AL, Brown MD, Hudlicka $\mathrm{O}$ : Unorthodox angiogenesis in skeletal muscle. Cardiovasc Res 2001;49:634-646.

52 Styp-Rekowska B, Hlushchuk R, Pries AR, Djonov V: Intussusceptive angiogenesis: pillars against the blood flow. Acta Physiol (Oxf) 2011;202:213-223.

53 Hirschberg RM, Plendl J: Pododermal angiogenesis and angioadaptation in the bovine claw. Microsc Res Tech 2005;66:145155.

54 Macchiarelli G, Jiang JY, Nottola SA, Sato E: Morphological patterns of angiogenesis in ovarian follicle capillary networks: a scanning electron microscopy study of corrosion cast. Microsc Res Tech 2006;69:459-468.

55 Djonov V, Andres AC, Ziemiecki A: Vascular remodelling during the normal and malignant life cycle of the mammary gland. Microsc Res Tech 2001;52:182-189.

56 Van Steenkiste C, Trachet B, Casteleyn C, van Loo D, Van Hoorebeke L, Segers P, Geerts A, Van Vlierberghe H, Colle I: Vascular corrosion casting: analyzing wall shear stress in the portal vein and vascular abnormalities in portal hypertensive and cirrhotic rodents. Lab Invest 2010;90:15581572.

57 Konerding MA, Turhan A, Ravnic DJ, Lin M, Fuchs C, Secomb TW, Tsuda A, Mentzer SJ: Inflammation-induced intussusceptive angiogenesis in murine colitis. Anat Rec 2010; 293:849-857.

58 Rossi-Schneider TR, Verli FD, Marinho SA Yurgel LS, De Souza MA: Study of intussus- ceptive angiogenesis in inflammatory regional lymph nodes by scanning electron microscopy. Microsc Res Tech 2010;73:1419.

59 Notoya M, Shinosaki T, Kobayashi T, Sakai $\mathrm{T}$, Kurihara $\mathrm{H}$ : Intussusceptive capillary growth is required for glomerular repair in rat Thy-1.1 nephritis. Kidney Int 2003;63: 1365-1373.

60 Wnuk M, Hlushchuk R, Tuffin G, Huynh Do U, Djonov V: The effects of PTK787/ ZK222584, an inhibitor of VEGFR and PDGFR $\beta$ pathways, on intussusceptive angiogenesis and glomerular recovery from Thy1.1 nephritis. Am J Pathol 2011;178: 1899-1912.

61 Patan S, Munn LL, Jain RK: Intussusceptive microvascular growth in a human colon adenocarcinoma xenograft: a novel mechanism of tumor angiogenesis. Microvasc Res 1996;51:260-272.

62 Heindryckx F, Mertens K, Charette N, Vandeghinste B, Casteleyn C, Van Steenkiste C, Slaets D, Libbrecht L, Staelens S, Starkel P, Geerts A, Colle I, Van Vlierberghe H: Kinetics of angiogenic changes in a new mouse model for hepatocellular carcinoma. Mol Cancer 2010;9:14.

63 Nico B, Crivellato E, Guidolin D, Annese T, Longo V, Finato N, Vacca A, Ribatti D: Intussusceptive microvascular growth in human glioma. Clin Exper Med 2010;10:93-98.

64 Vuorio T, Jauhiainen S, Yla-Herttuala S: Proand anti-angiogenic therapy and atherosclerosis with special emphasis on vascular endothelial growth factors. Expert Opin Biol Ther 2012;12:79-92.

65 le Noble F, Fleury V, Pries A, Corvol P, Eichmann A, Reneman RS: Control of arterial branching morphogenesis in embryogenesis: go with the flow. Cardiovasc Res 2005;65: 619-628.

-66 Al-Kilani A, Lorthois S, Nguyen TH, Le Noble F, Cornelissen A, Unbekandt M, Boryskina O, Leroy L, Fleury V: During vertebrate development, arteries exert a morphological control over the venous pattern through physical factors. Phys Rev E Stat Nonlin Soft Matter Phys 2008;77:051912.

67 Clarke ER, Clarke EL: Microscopic observations of the growth of blood capillaries in the living mammal. Am J Anat 1939;64:251299 .

68 Lee GS, Filipovic N, Miele LF, Simpson DC, Giney B, Konerding MA, Tsuda A, Mentzer SJ: Blood flow shapes intravascular pillar geometry in the chick chorioallantoic membrane. J Angiogenes Res 2010;2:11.

-69 Otrock ZK, Makarem JA, Shamseddine AI: Vascular endothelial growth factor family of ligands and receptors: review. Blood Cells Mol Dis 2007;38:258-268.

70 Makanya AN, Hlushchuk R, Baum O, Velinov N, Ochs M, Djonov V: Microvascular endowment in the developing chicken embryo lung. Am J Physiol Lung Cell Mol Physiol 2007;292:L1136-L1146. 
71 Baum O, Suter F, Gerber B, Tschanz SA, Buergy R, Blank F, Hlushchuk R, Djonov V: VEGF-A promotes intussusceptive angiogenesis in the developing chicken chorioallantoic membrane. Microcirculation 2010; 17:447-457.

72 Kurz H, Burri PH, Djonov VG: Angiogenesis and vascular remodeling by intussusception: from form to function. News Physiol Sci 2003; 18:65-70.

73 Patan S: TIE1 and TIE2 receptor tyrosine kinases inversely regulate embryonic angiogenesis by the mechanism of intussusceptive microvascular growth. Microvasc Res 1998; $56: 1-21$.

-74 Thurston G, Suri C, Smith K, McClain J, Sato TN, Yancopoulos GD, McDonald DM: Leakage-resistant blood vessels in mice transgenically overexpressing angiopoietin-1. Science 1999;286:2511-2514.

75 Thurston G, Wang Q, Baffert F, Rudge J, Papadopoulos N, Jean-Guillaume D, Wiegand S, Yancopoulos GD, McDonald DM: Angiopoietin 1 causes vessel enlargement, without angiogenic sprouting, during a critical developmental period. Development 2005;132: 3317-3326.

-76 De Spiegelaere W, Cornillie P, Van den Broeck W: Immunohistochemical detection of the angiopoietins during porcine metanephric kidney development. Acta Histochem 2011;113:585-590.

77 Winnik S, Klinkert M, Kurz H, Zoeller C, Heinke J, Wu YX, Bode C, Patterson C, Moser M: HoxB5 induces endothelial sprouting in vitro and modifies intussusceptive angiogenesis in vivo involving angiopoietin-2. Cardiovasc Res 2009;83:558-565.

78 Zhang JH, Cao RH, Zhang Y, Jia TH, Cao YH, Wahlberg E: Differential roles of PDGFR-alpha and PDGFR-beta in angiogenesis and vessel stability. FASEB J 2009;23: 153-163.

79 Taylor AC, Seltz LM, Yates PA, Peirce SM: Chronic whole-body hypoxia induces intussusceptive angiogenesis and microvascular remodeling in the mouse retina. Microvasc Res 2010;79:93-101.

-80 Hanze J, Weissmann N, Grimminger F, Seeger W, Rose F: Cellular and molecular mechanisms of hypoxia-inducible factor driven vascular remodeling. Thromb Haemost 2007;97:774-787.

-81 De Spiegelaere W, Cornillie P, Van den Broeck W: Localization of erythropoietin in and around growing cartilage. Mol Cell Biochem 2010;337:287-291.

-82 Rankin EB, Biju MP, Liu QD, Unger TL, Rha J, Johnson RS, Simon MC, Keith B, Haase $\mathrm{VH}$ : Hypoxia-inducible factor-2 (HIF-2) regulates hepatic erythropoietin in vivo. Clin Investig 2007;117:1068-1077.
83 Crivellato E, Nico B, Vacca A, Djonov V, Presta M, Ribatti D: Recombinant human erythropoietin induces intussusceptive microvascular growth in vivo. Leukemia 2004; 18:331-336.

84 Nico B, Annese T, Guidolin D, Finato N, Crivellato E, Ribatti D: Epo is involved in angiogenesis in human glioma. J Neurooncol 2011; 102:51-58.

85 Gavard J: Breaking the VE-cadherin bonds FEBS Lett 2009;583:1-6.

86 Debbaut C, Monbaliu D, Casteleyn C, Cornillie P, Van Loo D, Masschaele B, Pirenne J, Simoens P, Van Hoorebeke L, Segers P: From vascular corrosion cast to electrical analog model for the study of human liver hemodynamics and perfusion. IEEE Trans Biomed Eng 2011;58:25-35.

87 Gerhardt H, Betsholtz C: High resolution in situ confocal analysis of endothelial cells; in Augustin H (ed): Methods in Endothelial Cell Biology. Berlin, Springer, 2004, pp 313 323.

88 Fu YY, Tang SC: Optical clearing facilitates integrated $3 \mathrm{D}$ visualization of mouse ileal microstructure and vascular network with high definition. Microvasc Res 2010;80:512521.

89 Wagner RC, Czymmek K, Hossler FE: Confocal microscopy, computer modeling, and quantification of glomerular vascular corrosion casts. Microsc Microanal 2006;12:262268.

90 Staton CA, Reed MW, Brown NJ: A critical analysis of current in vitro and in vivo angiogenesis assays. Int J Exp Pathol 2009;90:195221.

$\checkmark 91$ Norrby K: In vivo models of angiogenesis. Cell Mol Med 2006;10:588-612.

92 Polykandriotis E, Arkudas A, Beier JP, Dragu A, Rath S, Pryymachuk G, Schmidt VJ, Lametschwandtner A, Horch RE, Kneser U: The impact of VEGF and bFGF on vascular stereomorphology in the context of angiogenic neo-arborisation after vascular induction. J Electron Microsc (Tokyo) 2011;60: 267-274.

93 Auerbach R, Lewis R, Shinners B, Kubai L, Akhtar N: Angiogenesis assays: a critical overview. Clin Chem 2003;49:32-40.

94 Levin M, Ewald A, McMahon M, Werb Z, Mostov K: An in vitro model of intussusceptive angiogenesis. FASEB J 2006;20.

95 Hirschberg RM, Sachtleben M, Plendl J: Electron microscopy of cultured angiogenic endothelial cells. Microsc Res Tech 2005;67: 248-259.

96 Bahramsoltani M, Plendl J: A new in vitro model to quantify angiogenesis. ALTEX 2004;21:227-244

$\checkmark 97$ Young EW, Simmons CA: Macro- and microscale fluid flow systems for endothelial cell biology. Lab Chip 2010;10:143-160.

$\checkmark 98$ Bogle IDL, Allen R, Sumner T: The role of computer aided process engineering in physiology and clinical medicine. Comput Chem Eng 2010;34:763-769.
$\$ 99$ Palsson B: The challenges of in silico biology. Nat Biotechnol 2000;18:1147-1150

100 Godde R, Kurz H: Structural and biophysical simulation of angiogenesis and vascular remodeling. Dev Dyn 2001;220:387-401.

101 Szczerba D, Szekely G: Computational model of flow-tissue interactions in intussusceptive angiogenesis. J Theor Biol 2005; 234:87-97.

102 Filipovic N, Tsuda A, Lee GS, Miele LF, Lin M, Konerding MA, Mentzer SJ: Computational flow dynamics in a geometric model of intussusceptive angiogenesis. Microvasc Res 2009;78:286-293.

103 Szczerba D, Kurz H, Szekely G: A computational model of intussusceptive microvascular growth and remodeling. J Theor Biol 2009;261:570-583.

104 Nguyen TH, Eichmann A, Le Noble F, Fleury V: Dynamics of vascular branching morphogenesis: the effect of blood and tissue flow. Phys Rev E Stat Nonlin Soft Matter Phys 2006;73:061907.

105 Kusters B, Leenders WP, Wesseling P, Smits D, Verrijp K, Ruiter DJ, Peters JP, van der Kogel AJ, de Waal RM: Vascular endothelial growth factor-A(165) induces progression of melanoma brain metastases without induction of sprouting angiogenesis. Cancer Res 2002;62:341-345.

106 Holash J, Maisonpierre PC, Compton D, Boland P, Alexander CR, Zagzag D, Yancopoulos GD, Wiegand SJ: Vessel cooption, regression, and growth in tumors mediated by angiopoietins and VEGF. Science 1999; 284:1994-1998.

107 Kilarski W, Samolov B, Petersson L, Kvanta A, Gerwins P: Biomechanical regulation of blood vessel growth during tissue vascularization. Nat Med 2009;15:657-U145.

108 Paulis YW, Soetekouw P, Verheul HM, Tjan-Heijnen VC, Griffioen AW: Signalling pathways in vasculogenic mimicry. Biochim Biophys Acta 2010;1806:18-28.

109 Maniotis AJ, Folberg R, Hess A, Seftor EA, Gardner LM, Pe'er J, Trent JM, Meltzer PS, Hendrix MJ: Vascular channel formation by human melanoma cells in vivo and in vitro: vasculogenic mimicry. Am J Pathol 1999;155:739-752.

110 Chang YS, di Tomaso E, McDonald DM, Jones R, Jain RK, Munn LL: Mosaic blood vessels in tumors: frequency of cancer cells in contact with flowing blood. Proc Natl Acad Sci USA 2000;97:14608-14613

111 Zhang S, Zhang D, Sun B: Vasculogenic mimicry: current status and future prospects. Cancer Lett 2007;254:157-164.

112 Kässmeyer S, Plendl J, Custodis P, Bahramsoltani $\mathrm{M}$ : New insights in vascular development: vasculogenesis and endothelial progenitor cells. Anat Histol Embryol 2009; 38:1-11. 